EUROPEAN ORGANIZATION FOR NUCLEAR RESEARCH

European Laboratory for Particle Physics

Large Hadron Collider Project

LHC Project Report 375

\title{
Industrial Surfaces Behaviour Related to the Adsorption and Desorption of Hydrogen at Cryogenic Temperature
}

\author{
G. Moulard ${ }^{1}$, B. Jenninger ${ }^{1}$ and Y. Saito ${ }^{2}$
}

\begin{abstract}
The determination of the hydrogen adsorption capacity on different industrial surfaces has been carried out by measuring isothermal adsorption. First results show that the adsorption capacity is mainly determined by surface porosity. Therefore, the samples may be classified in two categories: smooth surfaces and porous surfaces.

Thermal desorption spectra reveal two adsorption energy levels for hydrogen physisorbed on porous materials, but only a single one on smooth samples. The value of the lowest energy level seems to be independent on the substrate nature. The physisorption process studied at low coverage, well below a monolayer, shows that these two levels are not well defined but an energy distribution exists for each of them.

The influences of the isotherm temperature and an annealing at $7 \mathrm{~K}$ of an adsorbed monolayer on hydrogen adsorption capacity have been studied.
\end{abstract}

1 CERN, LHC Division, Geneva, Switzerland

2 KEK, Tsukuba, Japan. Member of the CERN-Japan Collaboration to the LHC Project

6th European Vacuum Conference (EVC-6)

7-12 December 1999, Villeurbanne, France

\footnotetext{
Administrative Secretariat

LHC Division

CERN

CH - 1211 Geneva 23

Switzerland

Geneva, 11 April 2000
} 


\section{Introduction}

The use of superconducting magnets in the LHC Project provides cold bores at $1.9 \mathrm{~K}$. The accelerator vacuum chamber becomes an efficient cryopump. However, specific parts will only work at a temperature of $4.5 \mathrm{~K}$. In this region, the choice of a cryosorber material is of great importance. It must supply a large adsorption capacity, especially for hydrogen because its saturated vapour pressure at this temperature is above the maximum allowed vacuum pressure of the LHC.

In this study, two kinds of materials have been tested with smooth and porous surfaces. Hydrogen adsorption capacities, $\sigma_{\mathrm{m}}$, and hydrogen desorption energies, $\mathrm{E}_{\mathrm{d}}$, of all samples have been determined by recording respectively adsorption isotherms and thermal desorption spectra (T.D.S).

\section{Principles}

\section{a)Determination of the adsorption capacity}

The adsorption capacity, $\sigma_{\mathrm{m}}$ in molecules $/ \mathrm{cm}^{2}$, is estimated from adsorption isotherm measurements. The adsorption isotherm describes the equilibrium pressure evolution obtained by progressively increasing the gas coverage on a given surface which is maintained at a given temperature ${ }^{1}$. The sample is pumped under ultra-high vacuum before being cooled to the working temperature, between $3.7 \mathrm{~K}$ and $9 \mathrm{~K}$. The system is then isolated from the external pumping.

The volumetric method is used ${ }^{2}$. Small amounts of hydrogen are injected and the equilibrium pressure is measured. A steep pressure increase indicates the completion of the first monolayer on the surface and defines the adsorption capacity of the sample, indicating that the surface is saturated. The surface coverage, defined as the ratio between the number of adsorbed molecules and the adsorption capacity, is then equal to unity. The saturated vapour pressure $p_{0}$, of the gas at the working temperature is reached with additional injections.

\section{b)Determination of the adsorption energy}

Adsorption energies of physisorbed molecules are determined by increasing the sample temperature at a constant rate :

$$
T=\left(T_{o}+\beta t\right)
$$

The rate of the temperature change in our measurement, $\beta$, is in the range $10^{-3} \mathrm{~K} / \mathrm{s} ; T_{o}$ being the isotherm temperature. During the recording of the T.D.S, the desorbed molecules are evacuated by the external pumping system. Desorption peaks appear on the graph: pressure $=\mathrm{f}(T)$ (Fig. 1). Assuming a first order desorption, i.e. non associative desorption and no re-adsorption, the desorption energy is determined from the following equation ${ }^{3}$ : 


$$
\frac{E_{d}}{k T_{p}^{2}}=\frac{1}{\tau_{o} \beta} \exp \left(-\frac{E_{d}}{k T_{p}}\right)
$$

where $T_{P}$ is the temperature at the maximum of the desorption peak, $\tau_{o}$ is a constant equal to $10^{-13} \mathrm{~s}^{4}, E_{d}$ the desorption energy and $k$ the Boltzmann constant.

\section{Experimental set-up}

The experimental set-up is shown in Fig. 2. All samples consist of a tube inserted into a cryostat and the inner surface is studied. Two copper shields assure a homogeneous temperature along the sample, independent on the liquid helium. The non-uniform sample temperature between the top and the bottom when heating up does not exceed $1.5 \mathrm{~K}$. The cryostat can be filled either with liquid helium or with gaseous helium, depending on the working temperature. Samples have been tested in the range 3.7 K $-9 \mathrm{~K}$. Carbon resistance sensors are placed at the top, middle, and bottom of the sample to measure its temperature.

The number of injected hydrogen molecules is deduced from the pressure drop in a 2 litre reference volume, measured with a capacitance gauge. The ultra-high vacuum is monitored with a Bayart Alpert gauge, while for pressure values higher than 4. $10^{-6}$ Torr, a combined Pirani-Penning gauge is used. The transpiration factor is applied on pressure values.

Desorbed species during T.D.S are recorded with a residual gas analyser. It is found that the amounts of $\mathrm{O}_{2}, \mathrm{CO}, \mathrm{CO}_{2}, \mathrm{CH}_{4}$ and $\mathrm{H}_{2} \mathrm{O}$ are insufficient to cause the cryotrapping of hydrogen ${ }^{5}$.

\section{Samples studied}

Five different materials have been tested. The adsorption capacity is determined before and after an in situ bake out between $150^{\circ} \mathrm{C}$ and $250^{\circ} \mathrm{C}$, for 48 hours. The sample characteristics are presented below. Surfaces of samples (1) to (3) are considered as smooth while (4) and (5) exhibit a porous surface due to the anodization process.

1) Copper surface ${ }^{5}: 100 \mu \mathrm{m}$ thick copper colaminated stainless steel with a geometrical surface area of $2375 \mathrm{~cm}^{2}$. It is baked at $150^{\circ} \mathrm{C}$.

2) Electrochemical buffed SUS316L ${ }^{6}$ with a maximum roughness of $0.2 \mu \mathrm{m}$ and a geometrical surface area of $2050 \mathrm{~cm}^{2}$. The baking temperature is $200^{\circ} \mathrm{C}$.

3) TiZrV film: a film of $1 \mu \mathrm{m}$ thick TiZrV coated on sample (2) with a geometrical surface area of $770 \mathrm{~cm}^{2}$, supplied by CERN /EST Division. It is baked at $250^{\circ} \mathrm{C}$.

4) Anodised aluminium ${ }^{7}$ with a porous oxide layer of $40 \mu \mathrm{m}$ thick and a geometrical surface area of $631 \mathrm{~cm}^{2}$, delivered by Jefferson Lab (U.S.A). The baking temperature is $150^{\circ} \mathrm{C}$. 
5) Anodised aluminium : a porous oxide layer with a real surface over geometrical surface ratio of 240, and a geometrical surface of $560 \mathrm{~cm}^{2}$, provided by KEK laboratory (Japan). The baking temperature is $150^{\circ} \mathrm{C}$.

\section{Results}

\section{a)Adsorption capacity}

The adsorption capacity for hydrogen has been determined on unbaked and baked samples. Figure 3 shows the adsorption isotherms at $4.2 \mathrm{~K}$. The graphical representation is not the one commonly used in the literature, but it allows us to compare, for a given pressure, the corresponding surface coverage of each material. The graph shows two distinct families of curves: smooth substrates with a capacity lower than $10^{16}$ molecules $/ \mathrm{cm}^{2}$, and porous surfaces that present a capacity larger than $8.10^{16}$ molecules $/ \mathrm{cm}^{2}$. The corresponding $\sigma_{\mathrm{m}}$ values are given in Table 1.

Once the completion of the first hydrogen monolayer is obtained on smooth materials, the pressure rises steeply up to the saturated pressure at a value which is approximately twice $\sigma_{\mathrm{m}}$. On a porous substrate, the pressure rises abruptly after saturation, but the saturated vapour pressure is not reached.

Table 1

Hydrogen adsorption capacity at $4.2 \mathrm{~K}$

\begin{tabular}{|c|c|c|c|}
\hline & $\begin{array}{l}\text { molecules } / \mathrm{cm}^{2} \text { at } \\
\text { saturation : } \sigma_{\mathrm{m}}\end{array}$ & $\begin{array}{l}\text { molecules } / \mathrm{cm}^{2} \text { at } \\
\mathrm{P}_{\text {sat }}\left(10^{-6} \text { Torr }\right): \sigma_{\text {sat }}\end{array}$ & $\begin{array}{l}\text { Ratio } \\
\sigma_{\mathrm{sat}} / \sigma_{\mathrm{m}}\end{array}$ \\
\hline \multicolumn{4}{|l|}{ SMOOTH SURFACES } \\
\hline Copper film unbaked & $6.0710^{15}$ & $1.4910^{16}$ & 2.45 \\
\hline $\begin{array}{l}\text { Electrochemical buffed } \\
\text { stainless steel unbaked }\end{array}$ & $2.3610^{15}$ & $4.0810^{15}$ & 1.73 \\
\hline $\begin{array}{ll}\begin{array}{l}\text { Electrochemical buffed } \\
\text { stainless steel baked }\end{array} & \\
\end{array}$ & $2.6810^{15}$ & $5.2210^{15}$ & 1.95 \\
\hline TiZrV film & $3.0510^{15}$ & $6.0210^{15}$ & 1.97 \\
\hline \multicolumn{4}{|l|}{ POROUS SURFACES } \\
\hline $\mathrm{Al}$ anodized unbaked (USA) & $1.2310^{17}$ & / & l \\
\hline $\mathrm{Al}$ anodized baked (USA) & $1.8010^{17}$ & 1 & I \\
\hline Al anodized (KEK) & $8.110^{16}$ & $1.1810^{17}$ & 1.46 \\
\hline
\end{tabular}

The influence of the in-situ baking process on surface capacity is deduced from Figure 3. This cleaning procedure enhances the adsorption capacity, but its efficiency is better on porous samples than on smooth ones. Bakeout also reduces the system background pressure. 
The influence of an annealing process on the adsorbed molecules distribution on a porous surface has been examined. At first, hydrogen is injected on an anodised aluminium surface at $4.2 \mathrm{~K}$ to obtain a surface coverage slightly higher than unity but with an equilibrium pressure lower than the saturation pressure. The measured pressure is then $1.5 .10^{-8}$ Torr. After an annealing at $7 \mathrm{~K}$ for 2 hours the pressure reading at $4.2 \mathrm{~K}$ is

$1.110^{-9}$ Torr.

\section{b)Adsorption energy}

Table 2 presents the hydrogen binding energies for all the samples, determined from their respective T.D.S. Due to the measurement method used, the given binding energies correspond to average values. The values in brackets refer to small desorption peaks partially hidden inside larger ones.

Two general considerations can be made :

- $\quad$ A varying amount of hydrogen is captured with an average energy, $\mathrm{E}_{\mathrm{d} 1}$, ranging from $17 \mathrm{meV}$ to $24 \mathrm{meV}$, independent of the substrate.

On porous samples, a second adsorption energy level, between $60 \mathrm{meV}$ and $76 \mathrm{meV}$ exists. This second peak can be observed only after the baking process.

Table 2

Hydrogen adsorption energy at $4.2 \mathrm{~K}$

\begin{tabular}{|l|c|c|c|}
\hline \multicolumn{1}{|c|}{ Sample } & Preparation & $\mathrm{Ed}_{1}(\mathrm{meV})$ & $\mathrm{Ed}_{2}(\mathrm{meV})$ \\
\hline SMOOTH SURFACES & & & No peak \\
\hline Copper film buffed & Baked & $17.5-18$ & No peak \\
\hline $\begin{array}{l}\text { Electrochemical buffed } \\
\text { stainless steel }\end{array}$ & Baked & 15.5 & $(43.5) \quad 62.5$ \\
\hline $\begin{array}{l}\text { Electrochemical } \\
\text { stainless steel }\end{array}$ & activated & 21 & No peak \\
\hline TiZrV film & & & No peak \\
\hline POROUS SURFACES & Unbaked & 17 & No peak \\
\hline Al anodized (USA) & Unbaked & 23 & $62-64 \quad(83)$ \\
\hline Al anodized (USA) & Baked & 18 & 60 \\
\hline Al anodized (USA) & Unbaked & 17 & \\
\hline Al anodized (KEK) & &
\end{tabular}

When the isotherm is measured at higher temperature or when the surface is not fully saturated at $4.2 \mathrm{~K}$, higher values of $\mathrm{E}_{\mathrm{d} 1}$ and of $\mathrm{E}_{\mathrm{d} 2}$ are observed, as shown in Table 3. T.D.S after an annealing at $7 \mathrm{~K}$, shows only one broad desorption peak extending from $30 \mathrm{meV}$ to $108 \mathrm{meV}$. 


\section{Table 3}

Hydrogen adsorption energy at $4.2 \mathrm{~K}$ for non saturated surfaces and at $7 \mathrm{~K}$ for saturated surfaces

\begin{tabular}{|l|c|c|c|}
\hline \multicolumn{1}{|c|}{ Sample } & Preparation & $\mathrm{Ed}_{1}(\mathrm{meV})$ & $\mathrm{Ed}_{2}(\mathrm{meV})$ \\
\hline $\begin{array}{l}\text { Electrochemical } \\
\text { buffed stainless steel }\end{array}$ & Not saturated & $16.5 \quad(45)$ & No peak \\
\hline Al anodized (USA) & $7 \mathrm{~K}$ baked & 27.5 & 82 \\
\hline Al anodized (USA) & Not saturated & 47 & 106 \\
\hline
\end{tabular}

The T.D.S of porous surfaces also gives the relative adsorption capacity corresponding to each adsorption energy level. Different growing modes of the first monolayer can be observed, depending on the isotherm temperature and on the surface coverage. At $7 \mathrm{~K}$, $99 \%$ of trapped hydrogen molecules are captured with an energy of $70 \mathrm{meV}$, while at $4.2 \mathrm{~K}, 60 \%$ are bound with approximately the same energy. For this latter temperature, at low coverage $(\theta=0.2)$, the T.D.S shows up a first and a second peak, respectively, at $47 \mathrm{meV}$ and $106 \mathrm{meV}$ instead of $18 \mathrm{meV}$ and $76 \mathrm{meV}$ as for a saturated surface $(\theta=1)$ (Fig. 4 and Table 3$)$.

The isotherm obtained at $3.7 \mathrm{~K}$, with the same sample shows a second desorption peak corresponding to an average binding energy lower than the one at $4.7 \mathrm{~K}$ (Fig. 5). Moreover, the smaller area of this peak, as compared to the one observed at $4.2 \mathrm{~K}$, indicates a lower capacity than at $4.2 \mathrm{~K}$.

\section{Discussion}

At $4.2 \mathrm{~K}$, the sorption capacity of hydrogen is higher on porous surfaces than on smooth ones by at least one order of magnitude. From the T.D.S, one concludes that the large adsorption capacity is due to the porosity.

The ratio between the real surface area and the geometrical area $\left(\mathrm{S}_{\mathrm{r}} / \mathrm{S}_{\mathrm{g}}\right)$ on smooth samples is close to unity. The saturated vapour pressure is reached at a coverage $\sigma_{\text {sat }}$ equal to twice the value of $\sigma_{\mathrm{m}}$, supposing that the adsorption capacity of the first and second monolayers for $\mathrm{H}_{2}$ are the same. The large $\mathrm{S}_{\mathrm{r}} / \mathrm{S}_{\mathrm{g}}$ ratio of a porous substrate is attributed to the surface porosity. A number of molecules, more than two orders of magnitude higher than the one needed for a smooth surface, is necessary to fill the pores and to form the first monolayer. The second monolayer corresponds to the one necessary to saturate a smooth surface. The steep pressure rise after the saturation is characteristic of a porous surface ${ }^{8}$. The saturated $\mathrm{H}_{2}$ vapour pressure, $\mathrm{p}_{\mathrm{o}}$, at $4.2 \mathrm{~K}$, is not reached with the porous sample. This phenomenon, called the capillary condensation is expressed mathematically by Kelvin's equation : the smaller the pore diameter, the lower the relative vapour pressure, $p / p_{o}{ }^{9}$.

Since electrochemical buffing is carried out by adding small abrasives to electrolyte liquid, this method may cause not only smoothness but also small cracks which are possible adsorption sites with higher energy than $E_{\mathrm{d} 1}$. 
Independent of the surface structure, on a surface saturated at $4.2 \mathrm{~K}$, some hydrogen molecules are physisorbed with an energy ranging from $15.5 \mathrm{meV}$ to $24.5 \mathrm{meV}$, in good agreement with the $22 \mathrm{meV}$ usually found in the literature ${ }^{10,11}$. It seems that the nature of the material does not strongly affect the lower energy level. One may therefore consider this energy level as a characteristic of hydrogen physisorption. On smooth surfaces, no hydrogen is adsorbed at other energy levels, indicating that this energy is characteristic for hydrogen adsorption on top of the surface, i.e. a surface without pores. The adsorption energy inside a pore is between $60 \mathrm{meV}$ and $76 \mathrm{meV}$; slightly lower than on charcoal $(80 \mathrm{meV})$ and on porous glass $(85 \mathrm{meV})^{4}$.

The large width of the peaks shown on the T.D.S is related to an adsorption energy distribution on the top surface and within the pores. In both cases, a local distortion of the interaction potential between the sample and the gas molecule exists as follows:

The top of the surface is liable to exhibit imperfections which include cleavage steps, dislocations and point defects. The defects produce heterogeneity on the surface $^{12}$ leading to an adsorption energy distribution. Adsorption energy on such defects is usually high $(47 \mathrm{meV})$ in comparison with the value on a perfectly flat substrate $(22 \mathrm{meV})$. Nevertheless, the number of $\mathrm{H}_{2}$ molecules adsorbed on such defects is small compared to the total quantity adsorbed on the top surface.

Within a pore, the interaction potential between an adsorbed molecule and the wall is strongly modified. The potential well is deeper than on the top surface, leading to higher adsorption energies. According to Zsigmondy's model, ${ }^{13}$ as the pressure is progressively increased, wider and wider pores are filled until, at the saturation pressure, the entire system is filled with condensate. The adsorption energy of a molecule inside a pore depends on the dimension of the adsorbate relative to the pore ${ }^{14}$ and the smaller the pore diameter, the higher the binding energy.

The T.D.S of an isotherm at $4.2 \mathrm{~K}$ with a relative coverage of 0.2 on a porous surface suggest the tendency for adsorbed molecules to migrate to the various defects. Hence, molecules come in contact with a greater number of substrate atoms, leading to an increase of the adsorption energy. At this low coverage, $\mathrm{H}_{2}$ molecules fill the high energy sites i.e. the smallest pores and surface defects, leading to high binding energies (106 meV within the pores and $47 \mathrm{meV}$ on the top surface). As the coverage increases, the mean binding energy decreases. On such "heterogeneous" surfaces, interactions with hydrogen molecules cannot be characterised by a single energy value 4 . Nevertheless, we can consider that two kinds of adsorption sites exist: on the top surface, where sites are defined by an average energy of $20 \mathrm{meV}$ for $\mathrm{H}_{2}$; and within the porosity, where the largest capacity is available on sites with an average energy of 70 $\mathrm{meV}$. It follows from this analysis that, as long as the interaction between adsorbed molecules can be neglected, an adsorption site can be defined as a definite position on the surface which will always physisorb a specific gas molecule with the same energy.

The sorption of a molecule is considered as effective if its sojourn time on the site is long enough. This parameter strongly depends on the temperature. Therefore, sites at $20 \mathrm{meV}$ cannot be considered as effective adsorption sites for an adsorption at 
$7 \mathrm{~K}$ since the mean sojourn time is 25 seconds. The adsorption capacity is reduced when the isotherm temperature increases because some adsorption sites become unavailable (Fig. 6). The number of available sites depends on the energy distribution of the sites.

Adsorption on defects and into small pores involves a diffusion mechanism of molecules, from low to higher energy sites. The diffusion process of $\mathrm{H}_{2}$ molecules is efficient at $7 \mathrm{~K}$ and molecules on the top surface can diffuse to sites corresponding to the surface defects or to porosity. At $3.7 \mathrm{~K}$, the diffusion is strongly reduced and $\mathrm{H}_{2}$ molecules are adsorbed where they impinge the surface. The rate of diffusion into the smallest pores is low and the porosity is not completely filled. As a consequence, the T.D.S shows a second desorption peak smaller in height than for the isotherm at $4.2 \mathrm{~K}$, and the number of occupied sites with energy higher than $80 \mathrm{meV}$ is considerably reduced.

The subsequent annealing at $7 \mathrm{~K}$ of the monolayer deposited at $4.2 \mathrm{~K}$ activates the diffusion such that all the pores are filled. The adsorption capacity is optimised which results in a reduction of the pressure.

The second desorption peak observed with an isotherm at $4.2 \mathrm{~K}$, on a porous substrate and with a coverage of $\theta=0.2$ and $\theta=1$ respectively, have been compared in Fig. 4. These peaks overlap at high temperature [35 K - $45 \mathrm{~K}]$. At low coverage, high energy sites are filled first if the diffusion is effective.

One assumption would be to consider in first approximation, this second desorption peak for $\theta=1$, as the sum of three peaks as shown in Fig. 7. Then, the peak with the highest energy (106 meV) should correspond to micropores with the lowest diameters; the second one has an energy of $82 \mathrm{meV}$ and the largest one, corresponds to the widest micropores and has an energy of $70 \mathrm{meV}$. Widest micropores also have the largest capacity ${ }^{15}$. The shape of this second desorption peak is linked to the micropore size distribution, i.e, pores with a diameter less than $20 \AA^{16}$.

\section{Conclusion}

Measurements of isotherm adsorption and of thermal desorption spectra of hydrogen at, and close to liquid helium temperature on different kinds of samples have been carried out. In this temperature range, hydrogen physisorption does not depend on the sample nature but depends on the surface structure. A binding energy around 20 $\mathrm{meV}$ is found for all the samples; it corresponds to the hydrogen adsorption on the top surface. The energy distribution around the $70 \mathrm{meV}$ peak is linked to the pore size distribution.

The annealing at $7 \mathrm{~K}$ of the adsorbed layer has revealed the importance of the surface diffusion process. The maximum sorption capacity is reached when the smallest pores are filled. Therefore, the concept of adsorption capacity at a given temperature, is closely related to the distribution of the first adsorbed monolayer into the pores. 


\section{References}

1 : D.M. Young, A.D. Crowell, Physical adsorption of Gases, (Butterworths, London, 1962) p.3.

2 J.P. Hobson, The Journal of Physical Chemistry, Vol 73, N 8 (1969).

${ }^{3}$ D.P. Woodruff, T.A. Delchar, Modern Techniques of Surface Science $2^{\text {nd }}$ edition, $p$ 521.

${ }^{4}$ P. A. Redhead, J. P. Hobson, E. V. Kornelsen, "The Physical Basis of Ultrahigh Vacuum", American Vacuum society classics.

${ }^{5}$ E. Wallén, J. Vac. Sci. Technol. A 14(5) (1996) p.2916.

${ }^{6}$ M. Baba et al. Proc. $15^{\text {th }}$ IS DEIV, Darmstadt,1992 p.3.

${ }^{7}$ M. G. Rao, P. Kneisel and J. Susta, Cryogenics, vol 34, (1994) p.377.

${ }^{8}$ E: Wallén, J. Vac. Sci. Technol. A 15(2), (1997), p. 265.

${ }^{9}$ S. J. Gregg and K. S. W. Sing “Adsorption, Surface area and Porosity", $2^{\text {nd }}$ edition 1982 Academic press, p. 112.

10 S. Andersson, L. Wilzén, M. Persson, Phys. Rev. B, 38(5), (1988), p. 2967.

${ }^{11}$ J. P. Hobson, J. Vac. Sci. Technol. A 13(3), (1995), p. 549.

${ }^{12}$ S. Ross and J. P. Oliver, "Physical Adsorption", Interscience, New-York (1964).

${ }^{13}$ A. Zsigmondy, Z. Anorg. Chem. 71, (1911), p. 356.

14 .D. H. Everett and J. C. Powl, J. Chem. Soc., Faraday Trans. I, 72, 619 (1976).

${ }^{15}$ M. J. Sparnaay, Surface Science, 9 (1968), p. 100.

16 IUPAC Manual of Symbols and Terminology, appendix 2, Pt. 1, Colloid and Surface Chemistry. Pure Appl. Chem. 31, 578 (1972). 


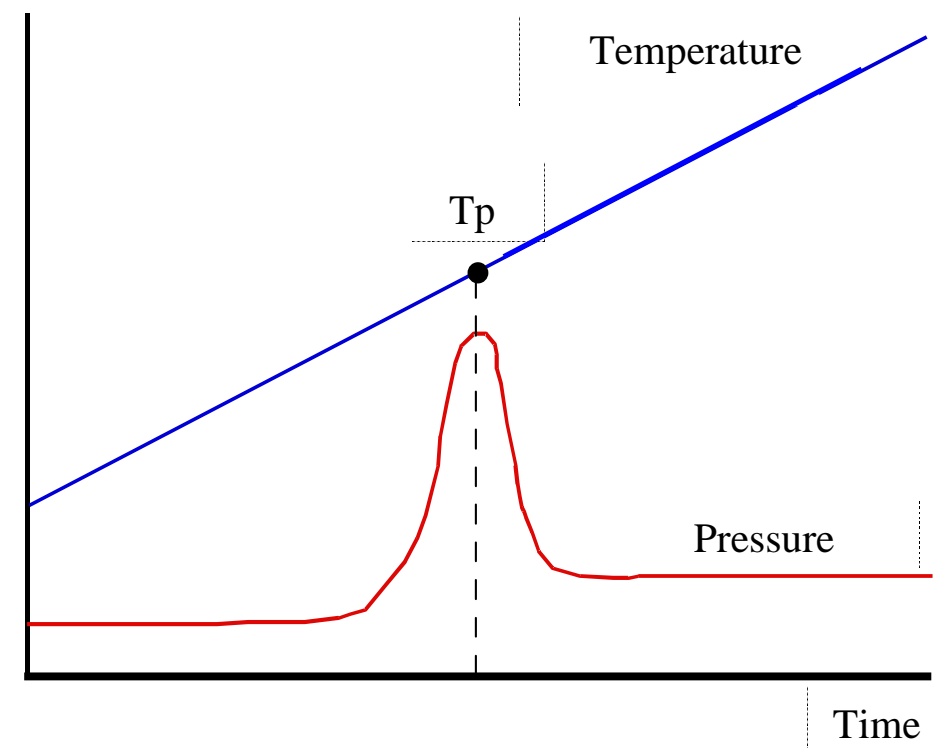

Figure 1 : Thermal Desorption Spectra (T.D.S) 


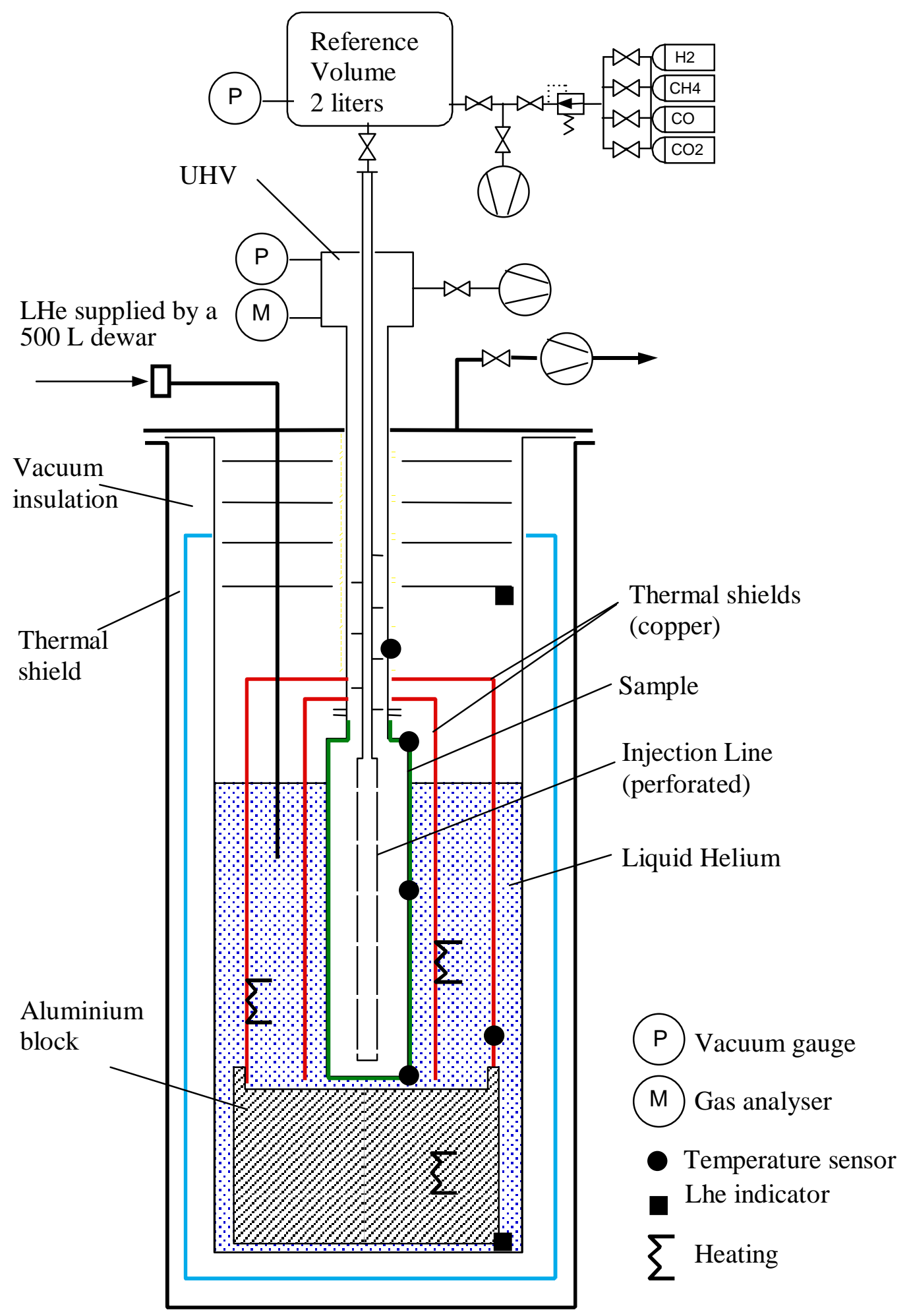

$\underline{\text { Figure } 2}$ : Experimental set-up for isotherm adsorption and thermal desorption spectra 


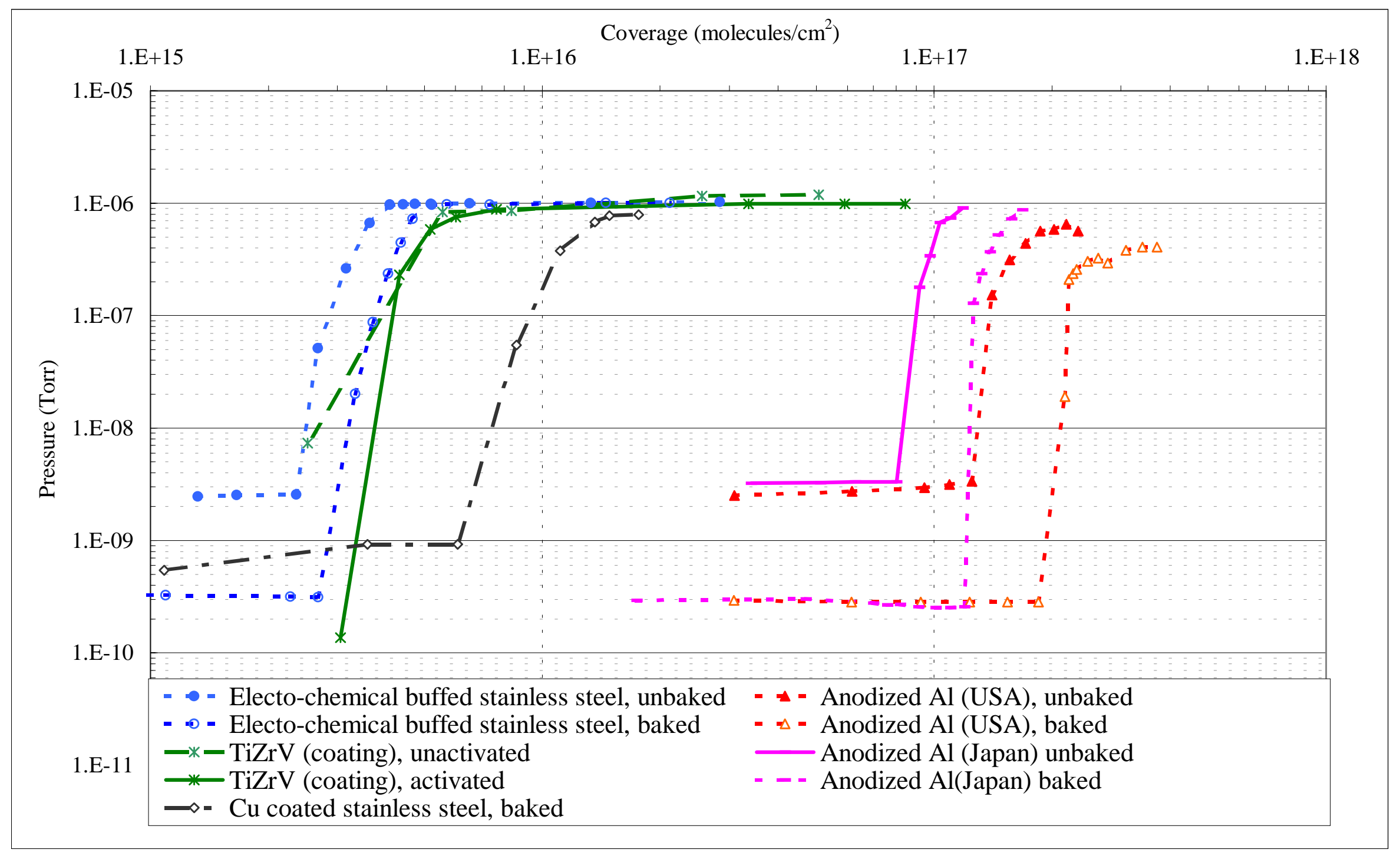

Figure 3 : Hydrogen adsorption isotherm at $4.2 \mathrm{~K}$ for various samples 


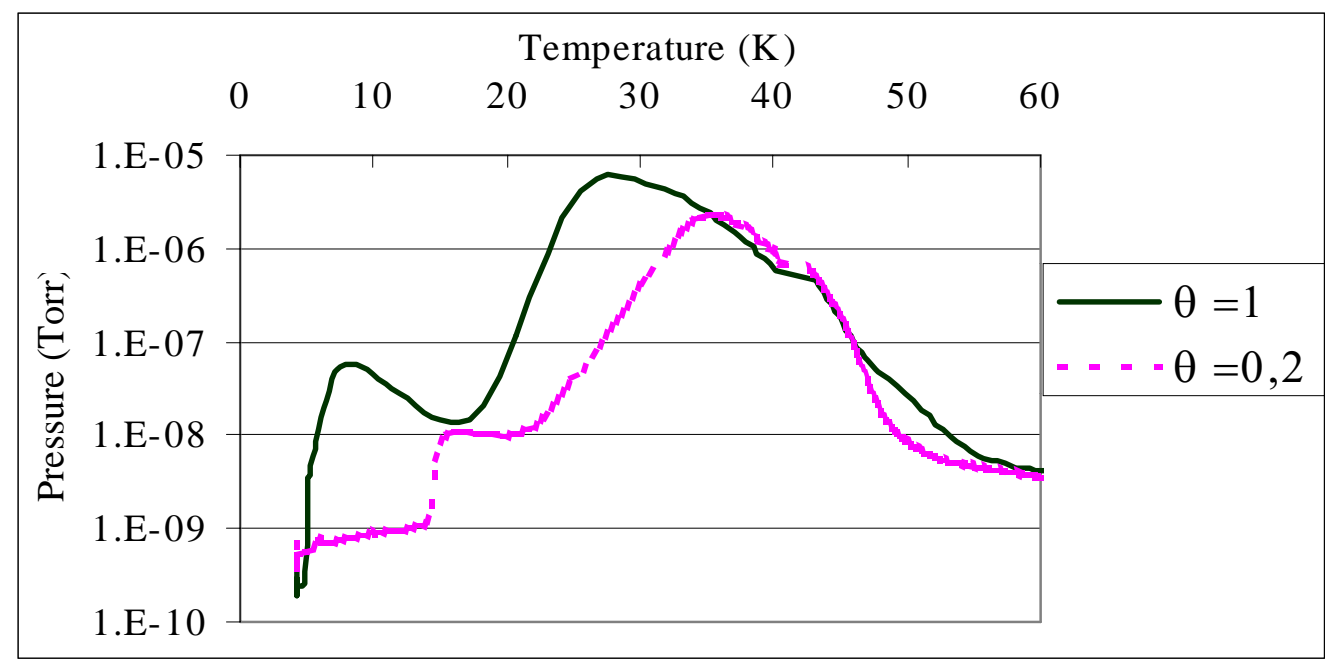

Figure 4 : T.D.S for anodized $\mathrm{Al}$ (sample 4) following an isotherm measurement at $4.2 \mathrm{~K}$, with 2 different coverages

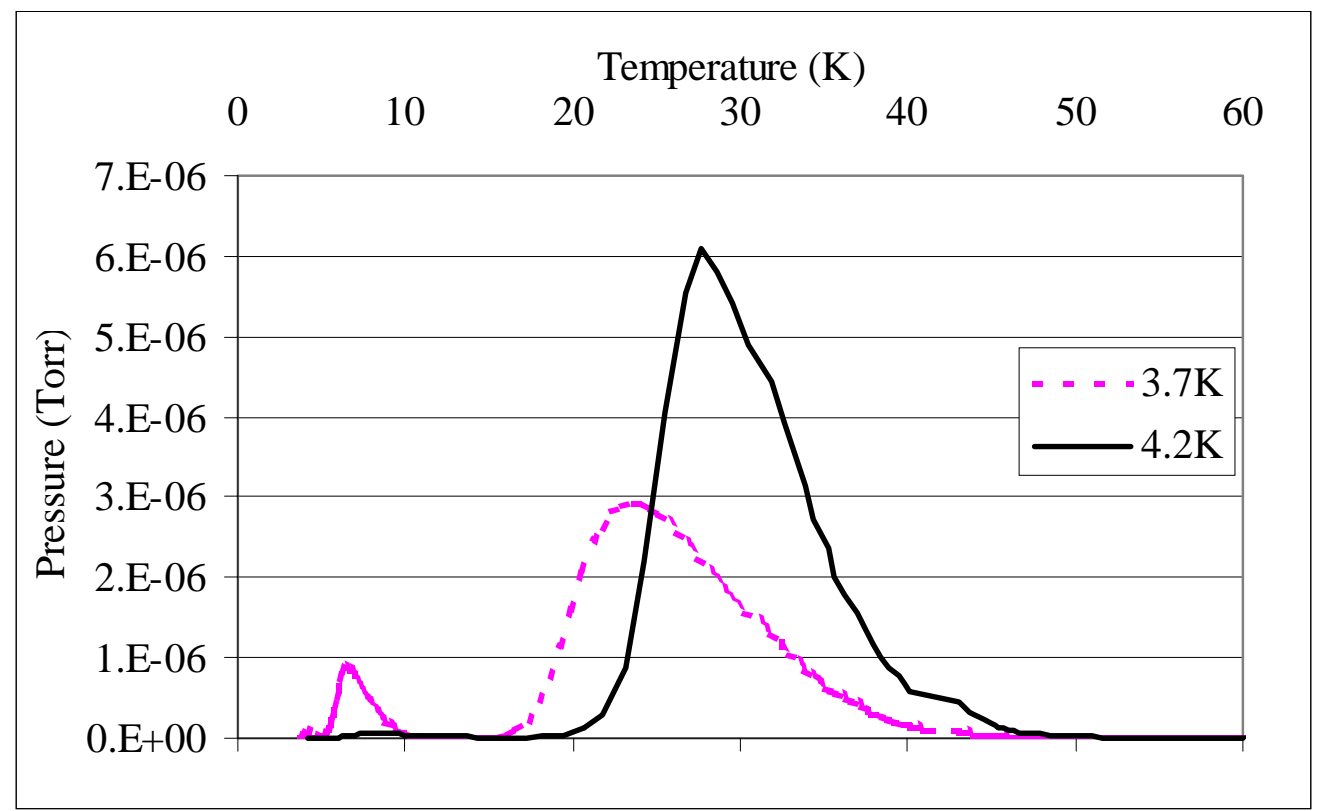

Figure 5 : T.D.S for anodized $\mathrm{Al}$ (sample 4) following an isotherm measurements at $3.7 \mathrm{~K}$ and $4.2 \mathrm{~K}$ 


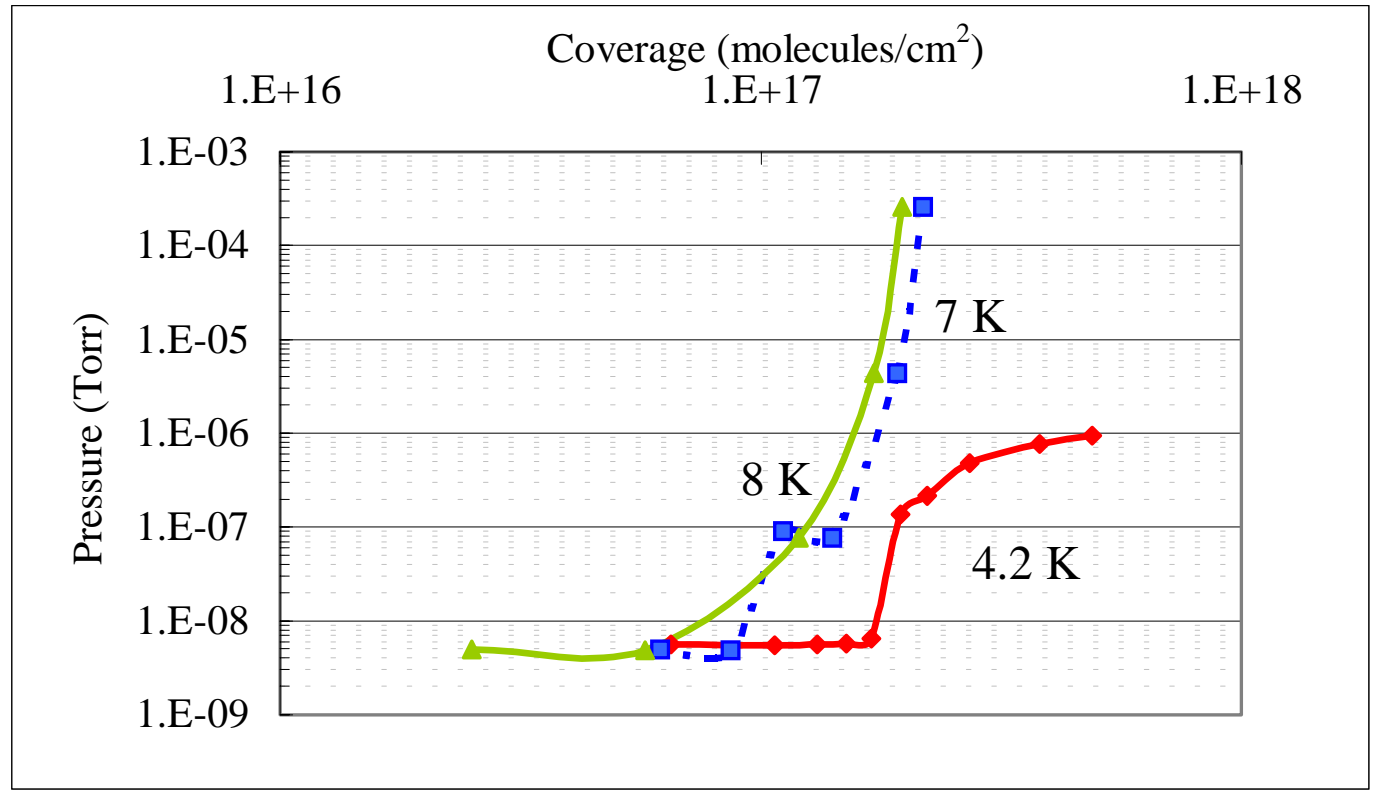

Figure 6 : Adsorption isotherms on anodised aluminium at 3 different temperatures

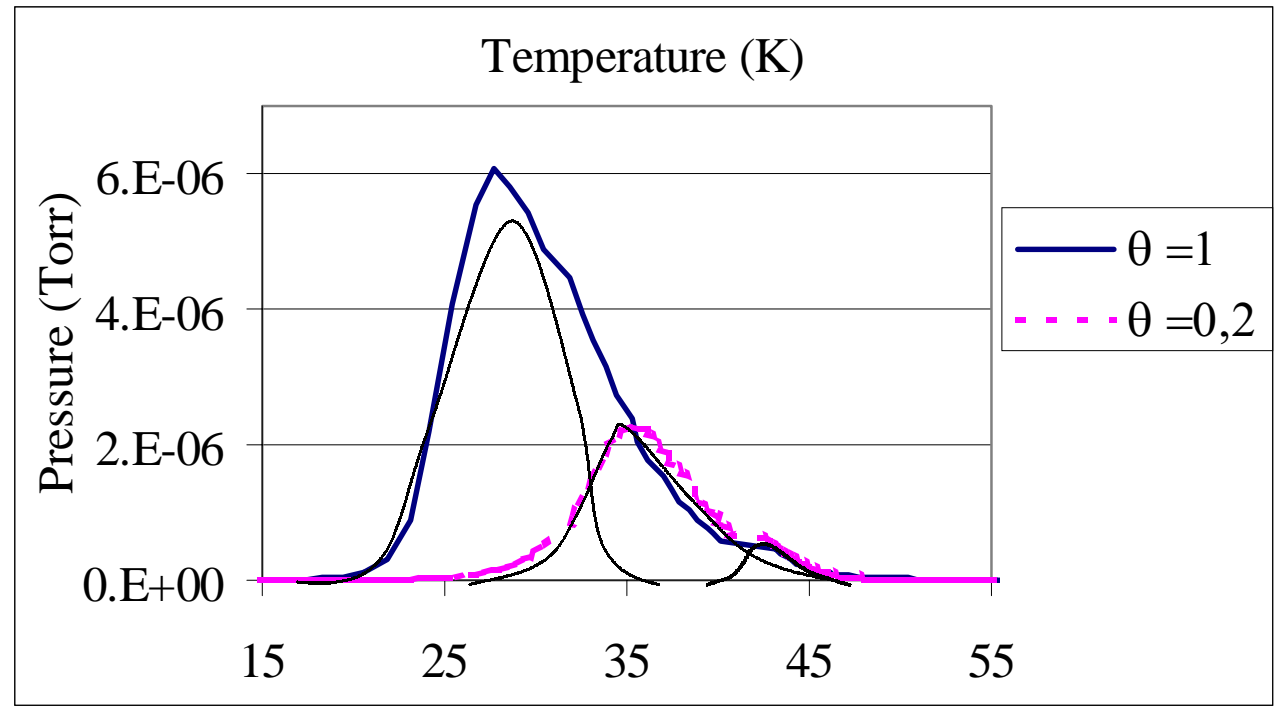

Figure 7 : Energy distribution within the microporosity 